\title{
OVERVIEW OF PAVEMENT MANAGEMENT SYSTEM IN KOREA AND ITS OPERATION RESULTS
}

\author{
Soo-Hyung Lee \\ 2311, Daehwa-Dong, ilsanseo-Gu, Goyang-Si \\ Gyeonggi-Do, 411-712 Republic of Korea \\ Korea Institute of Construction Technology \\ Highway Facility Research Div. Researcher \\ www.kict.re.kr \\ Tel)+82-31-9100-144 Fax)+82-31-9100-161 \\ shlee1@kict.re.kr
}

\author{
In-Kyoon Yoo \\ 2311, Daehwa-Dong, ilsanseo-Gu, Goyang-Si \\ Gyeonggi-Do, 411-712 Republic of Korea \\ Korea Institute of Construction Technology \\ Highway Facility Research Div. Director \\ www.kict.re.kr \\ Tel)+82-31-9100-167 Fax)+82-31-9100-161 \\ ikyoo@kict.re.kr
}

\begin{abstract}
Roads in Korea have been extended drastically in their lengths with high demand for highway construction caused by the economic upsurge in the early 1970s and they are playing a significant role as a key facility to support sustainable economic growth ever since. Importance of roads is growing even more as a social infrastructure indispensable to support industrial growth and improve quality of life.

Among various road components, pavement has a direct impact on the ride comfort of road users. It can also cause damage to, and energy consumption of vehicles. As the road pavement is damaged by vehicle traffic and environmental impacts over time, periodic maintenance is essential to keep pavement in good condition.

However, as the length of roads to be managed increased, costs required for operation and maintenance of roads rose accordingly, and as the costs increased, an objective, rational, and systematic arrangement for managing pavement was required. In other words, as many entities were competing over limited budget, the budgeting authority began to require evidence that apportioned budget was spent most efficiently. Therefore, road manager needs to manage road pavement in a more objective and systematic method unlike in the past and requires a pavement management approach that can meet such requirements systematically through various studies, analyses and forecasts.

Various inspection equipment and analysis systems have been introduced from advanced countries to ensure efficiency in national road pavement management since 1987 and efforts have made to adapt the latest technologies to local requirements.

This paper reviewed the status of national highway PMS in Korea and operated results of PMS in 2006 and analyzed the situation before and after introduction of PMS. As a result, it was analyzed that traffic volume was dramatically increased, but the pavement condition was improved and rehabilitation budget is decreased after introduction of PMS.
\end{abstract}

\section{KEYWORDS}

Pavement Management System, Maintenance, Road, Pavement Condition 


\section{INTRODUCTION}

Modern transportation system such as road, railway, port, airport and communication is the infrastructure of a nation that enables the people to live daily lives and to perform industrial activities. It is an important for an index of a nation's economic growth. Out of these transportation systems, the road, as the main artery of the land, takes approx. $90 \%$ of the traffic volume in Korea [2], playing the leading role of the economic growth. The importance of road is ever growing since the traffic demand increases and diversifies along with widespread globalization and internationalization trend, and hence, the demand on faster and cheaper transportation.

Because all Highway facilities become deteriorated as time goes by, an appropriate maintenance is required for a road to keep providing the target service. Among the Highway facilities, pavement is directly contacted by the vehicles, affects the riding comfort, and is related with damage on the vehicles and consumption of energy. As pavement gets damaged due to the traffic and the environmental effect, the road management institution performs timely maintenance activities within the limit of the budget to maintain the good pavement state.

Because the scale or cost for maintenance increases due to ever extending road length and increase of labor cost and other prices, however, the cost of road maintenance increases every year, and we cannot rely on individuals' experience and sense in determining the budget. We need the basis to make a decision, and to use the limited budget in an efficient method. In order to proactively meet the situation, road managers are required to manage the road facilities in a more objective and systematic method than before, and a systematic method is required to meet the requirements through various types of survey, analysis and estimation.

In this paper, the concept of pavement management system, an objective and systematic method of managing pavement, specifies the operation state of the Pavement Management System (PMS) introduced by the Ministry of Construction and Transportation, the 2006 operation results, the procedure of determining the section for maintenance for 2007 and the maintenance method, and compares and analyzes the difference between before and after PMS.

\section{PAVEMENT MANAGEMENT SYSTEM}

PMS is first introduced in 1970 to secure the performance of pavement in a reasonable and systematic method in USA where the vehicle transportation is well developed. Many advanced countries also adopt the system, and continue research and development activities to improve the system.

Under the traditional pavement management system where we give priority on the damaged road section (reactive maintenance), the following problems occur:

Analysis of pavement state through its service life shows that pavement generally maintains good condition for a few years, looses performance gradually over a long period of time, and once damages begin to occur, shows rapid deterioration. The reactive maintenance method of repairing the road section where pavement is severely damaged drops the average pavement state of the entire road network.

And also, reactive maintenance of the damages already occurred requires large scaled maintenance and high cost, increasing traffic control cost and user cost. For a road section with heavy traffic volume, this large scaled maintenance sometimes makes the user cost to take over $50 \%$ of the total cost during the service life of the pavement [1].

This reactive maintenance method does not provide a clear reference for the road management policy and the budget, resulting in difficulty in estimating and receiving appropriate level of budge.

On the other hand, using preventive maintenance on the appropriate section in time with a proper method enables them to maintain the all the pavement in good condition at lower cost. Determining when, where, how and to which level the maintenance will be performed is a complex question to be handled through various types of analysis such as Life Cycle Costing (LCC) that considers not only the current cost but also that to be resulted from the future maintenance [3, 4]. We cannot rely too much on individuals' experience and sense in determining the 
maintenance with such diverse and complex problems. Any judgment made based on economical efficiency in terms of an individual sense can be inefficient in the aspect of LCC.

To find such unreasonableness and manage pavement in an efficient method, it is required to systemize overall management of pavement [5]. The Pavement Management System (PMS) is the reification of this concept.

PMS largely relies on development of the fast and safe testing equipment, the computer technology and the optimization technique as the cost for maintenance of road pavement increases sharply. As the technologies advance, the PMS technology is also under development. Also, the Assess Management System that manages overall road facilities including pavement, bridge and tunnel is now under review and study.

\section{NATIONAL HIGHWAY PMS}

\subsection{Outline}

PMS is the procedure of determining the maintenance section, the method and the priority of the next year though various kinds of test and analysis for the road pavement under the management of the Ministry of Construction and Transportation (MOCT). PMS is operated by Korea Institute of Construction Technology (KICT) and the maintenance is performed by MOCT.

\subsection{Selection and survey of 2006 survey section}

The pavement database was established after 4 years of survey work started from 1986 when the system was introduced from France. At the beginning of each year, we collect and file the data of the previous year, such as the maintenance results, the traffic volume and the section for which maintenance is requested; supplement and update the DB; and select the survey section in consideration of capacity of the test devices and the budget for the next year.

The survey section indicates the section deemed to require maintenance in priority. To select the survey section, we modify and supplement various types of data every year. We select the survey sections by excluding the sections deemed to have good pavement state and the sections which must be excluded.

As of the end of 2005, the total length of national roads was $14,224 \mathrm{~km}$. When excluding unpaved road, the unopened road, the section managed by the competent city, the roads in Jeju-do and the concrete pavement sections, the PMS target section was $11,195 \mathrm{~km}$. Out of the PMS target section, the building sections, the sections found to have good pavement condition in 2005 test and the sections for 2005 budget are excluded, and 7,108km is the 2006 PMS target section.

From the 2006 PMS target sections, 2006 survey section $2,663 \mathrm{~km}(3,592 \mathrm{~km}$ when converted into 2lane) was selected. The 2006 survey section consisted of the sections with service life of 6 years or more, the sections with service life of not more than 7 years but which were not allocated with 2005 budget, the 2006 requested sections and not included in the above sections, and the sections with $\mathrm{MCI}^{1} 4$ or higher. Figure 1 shows the flow of 2006 survey sections.

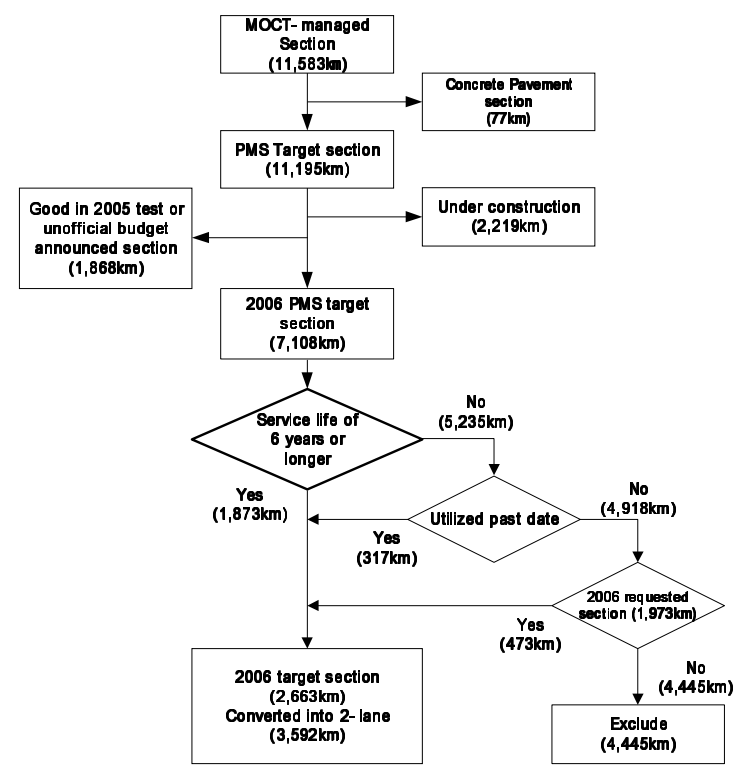

Figure 1. 2006 Survey Section Selection Flow

\footnotetext{
${ }^{1}$ MCI (Maintenance Control Index): Road surface index developed by Japanese Department of Construction in reference to PSI of USA.
} 
For the selected survey sections, we used $\mathrm{ARAN}^{2}$ to test crack, rutting and longitudinal roughness.

\subsection{Selection and survey homogeneous section}

From the survey sections, the test analysis sections are selected in consideration of the test conditions and budget of the year. In other words, we select the test analysis sections among the survey sections in consideration of the road surface test result, traffic volume and maintenance history, and by excluding the sections with good road surface, the sections with low traffic volume and the sections which have not been maintained long ago.

Once the test analysis sections are selected, these sections were categorized into homogeneous sections with relatively similar characteristics (homogeneous sections). Of the survey sections $(3,592 \mathrm{~km}), 2,011 \mathrm{~km}$ of test analysis sections were selected as the test analysis sections, and they were categorized into homogeneous sections with relatively similar pavement conditions in consideration of road surface condition, maintenance history and traffic volume. The sections with severe rutting, such as crossroad, were classified into particular sections (13 points, $1.9 \mathrm{~km})$. To evaluate the structural state for homogeneous sections, Falling Weight Deflectometer (FWD) and Ground Penetrating Radar(GPR) were used (Figure 2). In the particular sections, the cores are sampled from the fields to measure the depth of rutting.

\subsection{Survey result}

Figure 3 is the crack and rutting graph that shows the road surface damage in 150 homogeneous sections selected through 2006 PMS. Figure 4 shows the result of structural state of the homogeneous sections.

The surface condition survey result shows that the most common damage type is crack, and severe rutting is found mostly in the cross sections.

As showed in Figure 4, most sections are structurally stabilized, requiring no structural reinforcement but only the functional maintenance of the road surface depending on the level of damage.

${ }^{2}$ ARAN (Auto Road Analyzer): Automatic road surface measuring device.
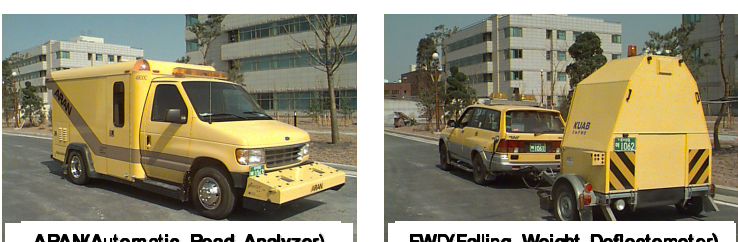

ARAN(Automatic Road Analyzer)

FWD(Falling Weight Deflectometer)
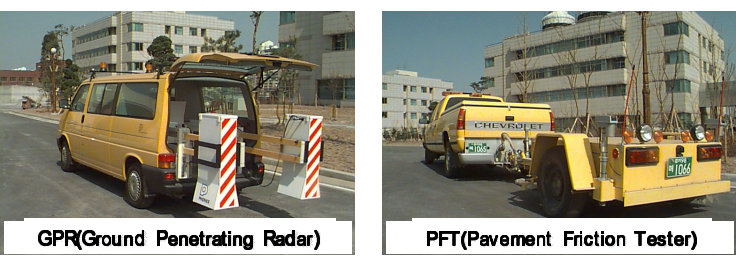

Figure 2. Site Survey Equipment

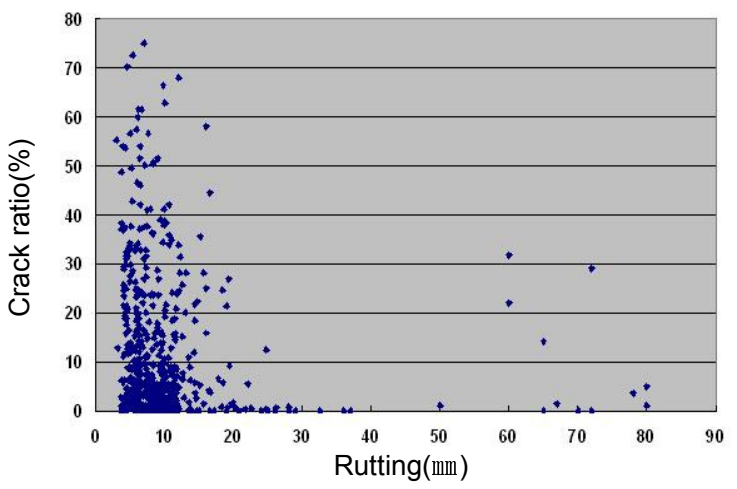

Figure 3. Surface Condition Survey Result

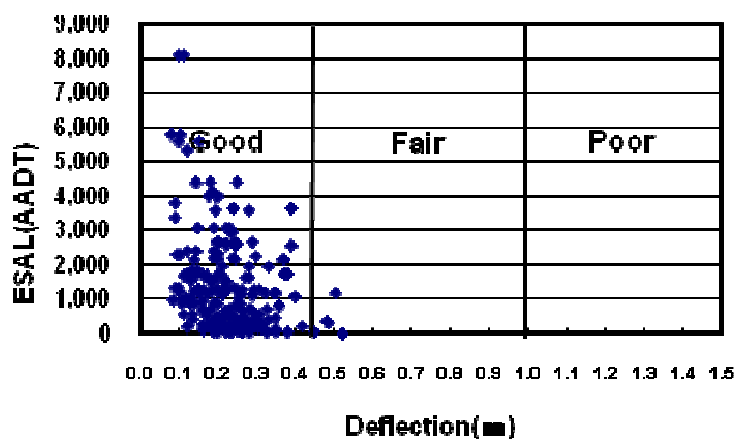

Figure 4. Structural Condition Survey Result

Figure 5 shows the distribution of each damage element and the MCI analysis result. 

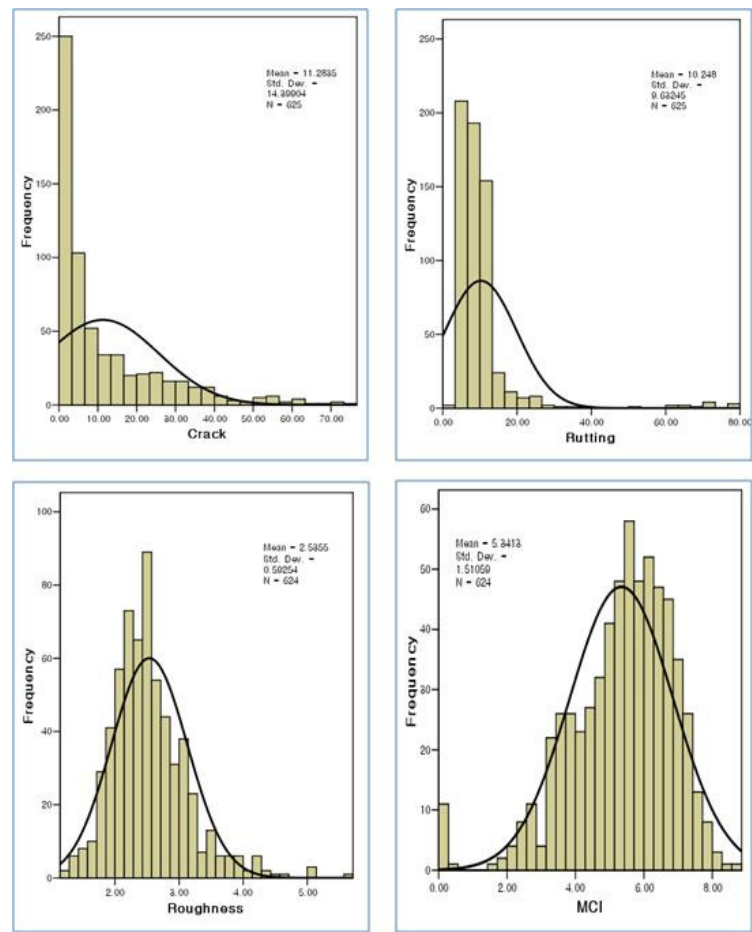

Figure 5. Distribution by Damage Element

The average of value by damage element is approx. $11 \%$ for crack, approx. $2.5 \mathrm{~mm} / \mathrm{km}$ for longitudinal roughness, and 5.3 for $\mathrm{MCI}^{3}$.

\subsection{Selection of maintenance method}

There are two ways of selecting the appropriate maintenance method and priority. One is to perform maintenance for the most severely damaged section first, and the other is to set the order depending on the optimum maintenance method and economical benefit based on the economical efficiency analysis result.

For 2006 paved road maintenance method was selected centering on the damage of pavement in principle, and the priority of the sections with minor damage was determined based on the economical efficiency analysis result. The maintenance method was selected based on the field test result and

\footnotetext{
${ }^{3}$ In Japan, MCI of 4 or lower is deemed to require a maintenance, and 3 or lower, an immediate maintenance.
}

overseas cases, and fixed through consultation with the experts.

To select a maintenance method, it is required to determine whether the maintenance is required, to select the preferential maintenance section depending on the level of damage, and then, to determine the method depending on the level of damage and characteristics of each method. Whether to perform the maintenance and the method of maintenance can be determined in the following procedure.

1) Principle

- $\quad$ Economic efficiency in preference $\rightarrow$ Damage in preference

- Good structural situation $\rightarrow$ Functional maintenance

- A preferred maintenance is performed if the crack distribution is $20 \%$ or higher, or rutting is $20 \mathrm{~mm}$ or deeper.

- Determine whether to perform a maintenance through economic efficiency analysis if the crack distribution is $5 \%$ or higher, or rutting is $12 \mathrm{~mm}$ or deeper.

2) Determine the appropriate maintenance method

- $5 \mathrm{~cm}$ Overlay

Rutting of less than $12 \mathrm{~mm}$ and crack of $20 \%$ or higher : preferred maintenance

$\square$ Rutting of less than $12 \mathrm{~mm}$ and crack of $10 \sim 20 \%$ : to check the economical efficiency

- $\quad$ Surface Treatment

Crack of $5 \sim 10 \%$ and rutting of less than $12 \mathrm{~mm}$

2-lane sections, ESAL 1,000(AADT) or lower

Review economic efficiency

- Polymerized Pavement : Rutting of $15 \mathrm{~mm}$ or deeper

- $\quad$ Milling 
$\square \quad$ Rutting of $20 \mathrm{~mm}$ or deeper

$\square$ Rutting of $15 \mathrm{~mm}$ or deeper and $\mathrm{ESAL}>1,000$ (AADT)

Figure 6 shows the maintenance method criteria and the field survey result, and Figure 7 showed the maintenance method selection flow.

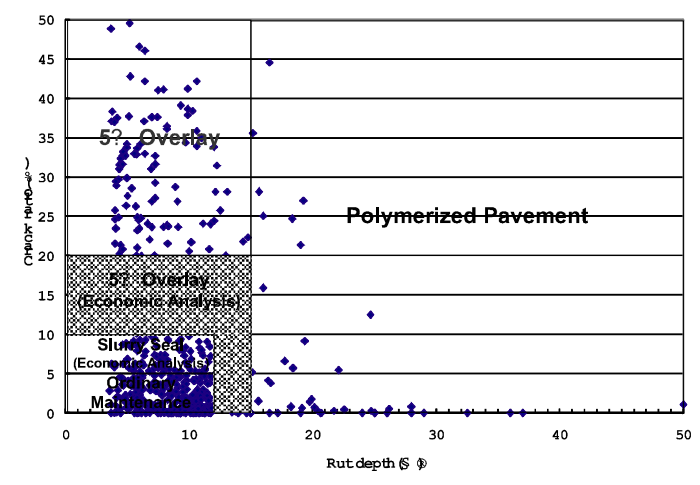

Figure 6. Maintenance Method by Damage on Road Surface

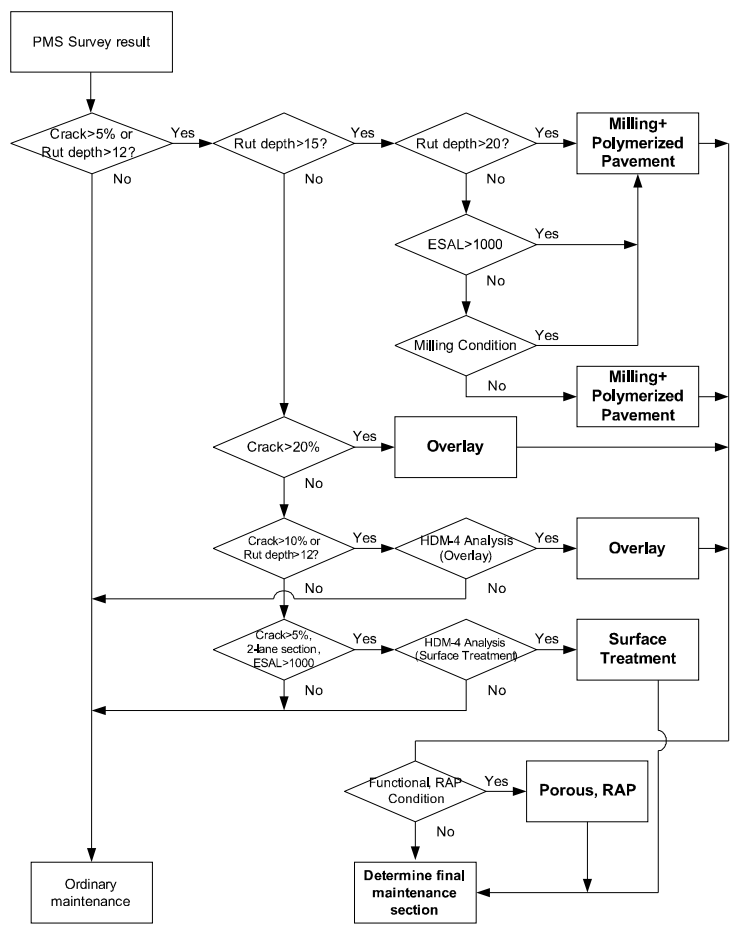

Figure 7. Maintenance Method Selection Flow
The maintenance priority was determined through economical efficiency test on the sections other than the preferred maintenance sections and the daily maintenance sections. Economic efficiency is analyzed for the $5 \mathrm{~cm}$ overlay sections with rutting of less than $12 \mathrm{~mm}$ and crack ratio of $10 \sim 20 \%$, and the surface finish sections. The maintenance priority was determined based on the difference of cost for 5 years of analysis period between when the maintenance is performed in the next year and when it is not performed (Net Present Value (NPV) considering discount rate 7\%). The HDM-4 program developed by the World Road Bank was used in this analysis. Figure 8 shows the results of maintenance method selection flow.

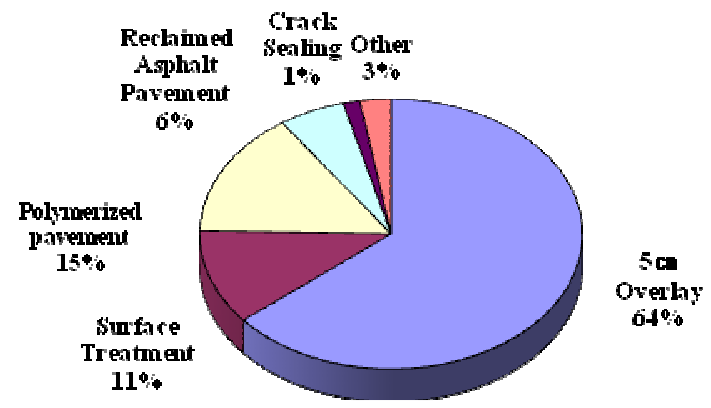

Figure 8. Selected Maintenance Methods

The total maintenance length is $572 \mathrm{~km}$ (converted into 2-lane road), and the total maintenance cost is 43.6 billion Won. The length for $5 \mathrm{~cm}$ overlay is $366 \mathrm{~km}$, which is $64 \%$ of the total maintenance length, and the rut-resistant maintenance is $86 \mathrm{~km}$, which is $15 \%$. The surface finish method and the field regeneration method take $11 \%$ and $6 \%$, respectively.

Table 1 shows the comparison of PMS maintenance methods selected between 2006 and 2007.

As described in the table, the total maintenance length and the cost in 2007 are reduced from those of 2006 by $131 \mathrm{~km}$ and 9.8 billion Won, respectively, due to the budget reduction. 
Table 1. Comparison between maintenance methods between 2006 and 2007

\begin{tabular}{|c|c|c|c|c|}
\hline \multirow{2}{*}{ Method } & $\begin{array}{c}\text { Length } \\
(\mathrm{km})\end{array}$ & $\begin{array}{c}\text { Cost } \\
\text { (million } \\
\text { Won) }\end{array}$ & $\begin{array}{c}\text { Length } \\
(\mathrm{km})\end{array}$ & $\begin{array}{c}\text { Cost } \\
\text { (million } \\
\text { Won) }\end{array}$ \\
\cline { 2 - 5 } & \multicolumn{2}{|c|}{2006} & \multicolumn{2}{|c|}{2007} \\
\hline $5 \mathrm{~cm}$ Overlay & 385 & 27,219 & 366 & 27,664 \\
\hline $\begin{array}{c}\text { Polymerized } \\
\text { pavement }\end{array}$ & 101 & 13,142 & 86 & 10,099 \\
\hline Surface Treatment & 128 & 3,695 & 65 & 2,089 \\
\hline Porous pavement & 34 & 4,633 & & \\
\hline RAP & 41 & 2,505 & 32 & 2,156 \\
\hline Crack seal & 13 & 205 & 8 & 130 \\
\hline Others & 1 & 2,002 & 15 & 1,455 \\
\hline Total & 703 & 53,401 & 572 & 43,583 \\
\hline
\end{tabular}

\section{ANALYSIS OF RESULT}

\subsection{Analysis of $2006 \mathrm{PMS}$ result}

Figures 9 10 show the result of analysis of service life and traffic volume of the maintenance section.

As shown in Figure 9, the average life of the 2007 service sections is 9.48 years. The lowest service life is 5 years, and there are numbers of sections with the service life of over 12 years, indicating that the pavement state is getting improved.

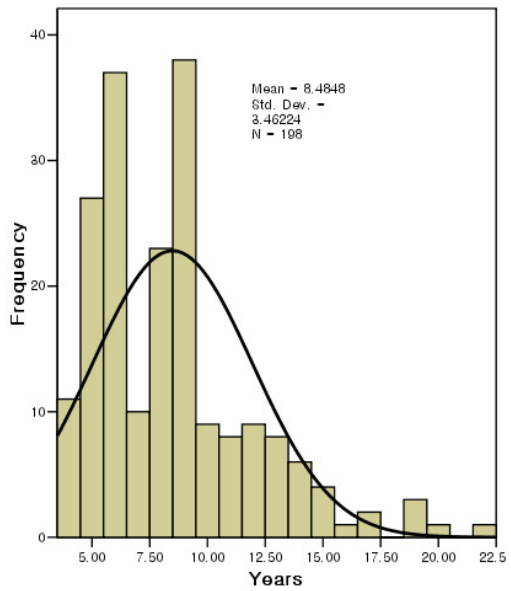

Figure 9. Service Life of Maintenance Section
However, it was found that early damage occurs in the sections or cross sections where many heavy vehicles pass. We suspect that it is because of extended use of polymer modified asphalt and the reinforced pavement using single-sized grain since later 1990 to control rutting.

In Figure 10 that shows the relationship between the service life and the traffic volume, we can find the section with shorter service life despite the low traffic volume. We will establish the cause through analysis and continue to improve the situation.

Figure 11 shows the relationship between maintenance history and traffic volume. As showed in Figure 11, higher traffic volume reduces time to damage, and causes early crack in new sections.

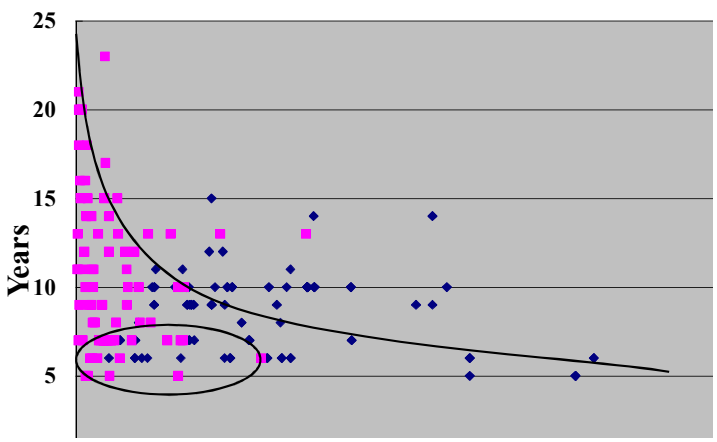

Figure 10. Service life and traffic volume in the maintenance section

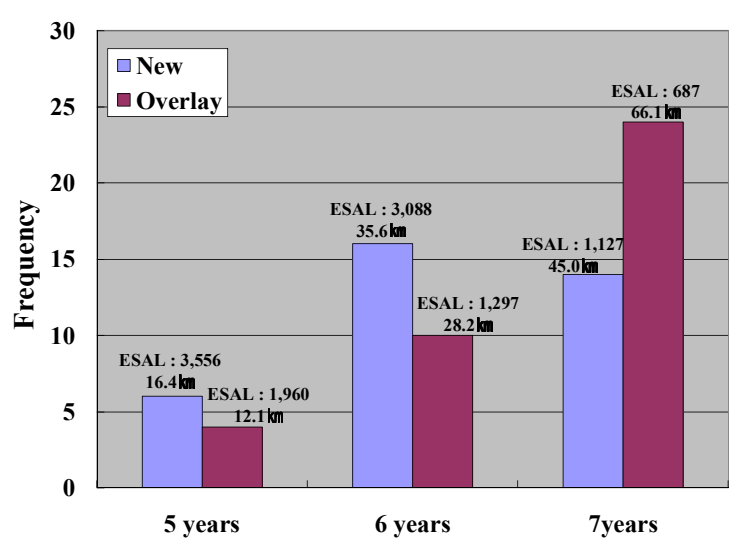

Figure 11. Relationship between traffic volume and early damage 


\subsection{Comparison between before and after PMS}

After introduction of PMS, the traffic volume on the conventional road has increased substantially. Despite such increase in traffic volume, crack ratio and roughness have been improved. The maintenance cost continuously increased since 1970s but is tending to downwards since 2001. Table 2 shows the traffic volume and pavement state in 1987 when PMS was introduced and in 2005. Figure 12 shows the traffic volume distribution and Figure 13 shows the trend of maintenance cost.

Table 2. Comparison between pavement state and traffic state

\begin{tabular}{|c|c|c|c|}
\hline Item & 1987 & 2006 & Remark \\
\hline ESAL(AADT) & 991 & 1,593 & Traffic volume in 2005 \\
\hline Crack ratio(\%) & 18.7 & 5.0 & \\
\hline Rut depth(mm) & 4.2 & 6.0 & \\
\hline Roughness $(\mathrm{m} / \mathrm{km})$ & 2.98 & 2.27 & \\
\hline $\begin{array}{l}\text { Maintenance cost } \\
(0.1 \text { billion Won })\end{array}$ & 1,151 & 765 & Present value in 2005 \\
\hline
\end{tabular}

Crack ratio and longitudinal roughness has been improved substantially when compared to 1987 when PMS is introduced, however, rutting has increased. We presume that it is because the heavy vehicle traffic has been doubled from introduction of PMS. Figures 14 16 show the comparison of crack ratio, rutting and longitudinal roughness distribution.

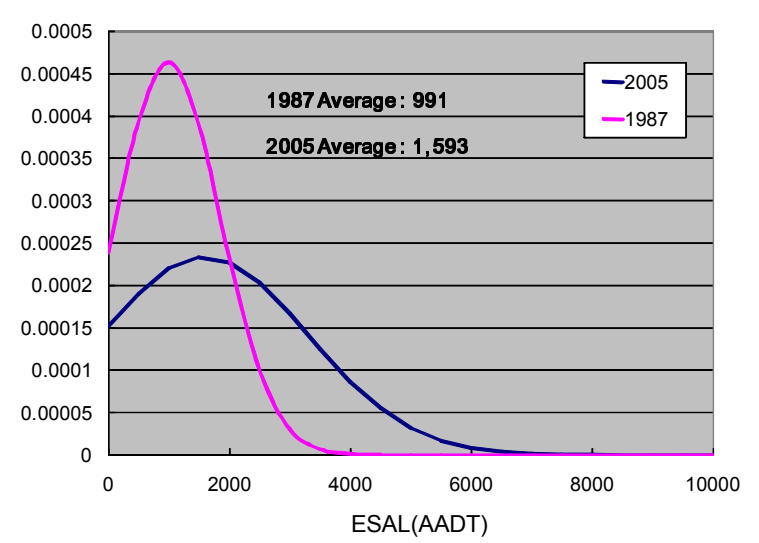

Figure 12. Traffic volume distribution

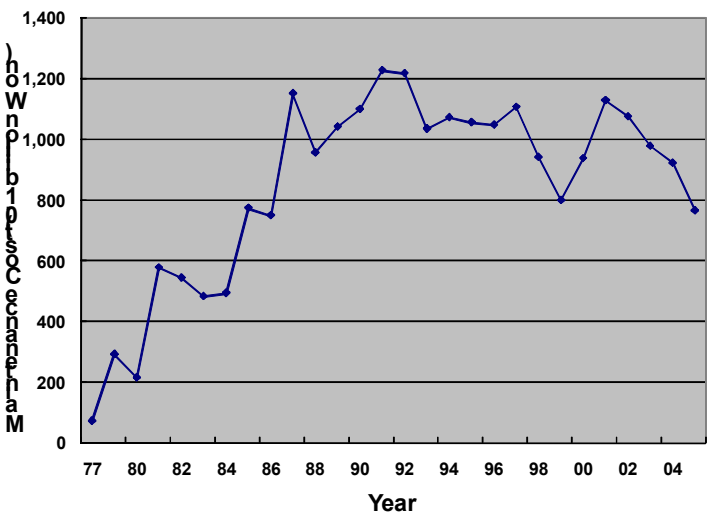

Figure 13. Maintenance cost trend (in '05 present value)

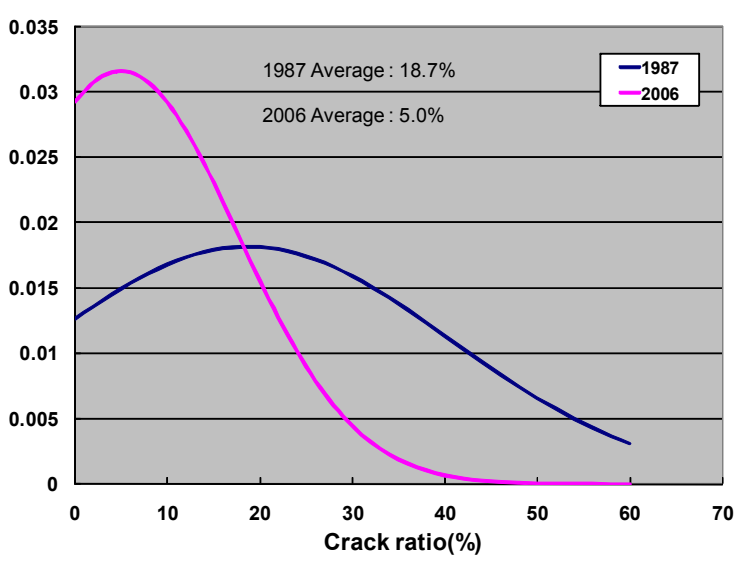

Figure 14. Comparison of crack ratio

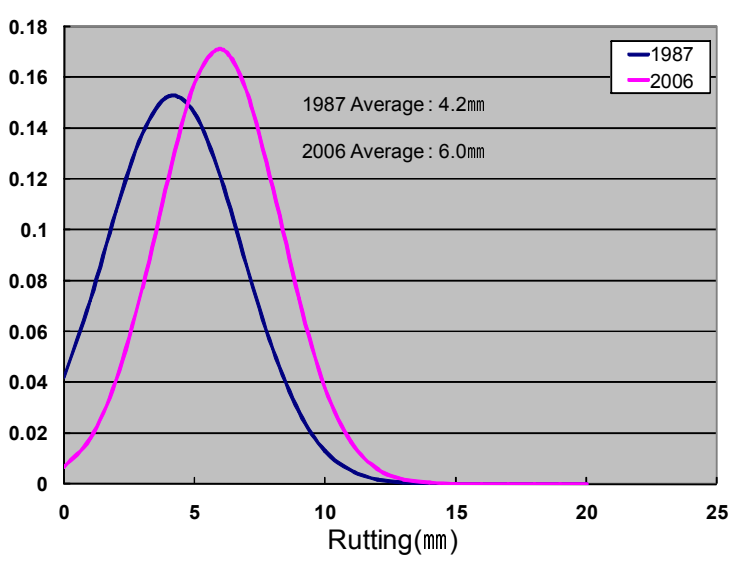

Figure 15. Comparison of rutting 


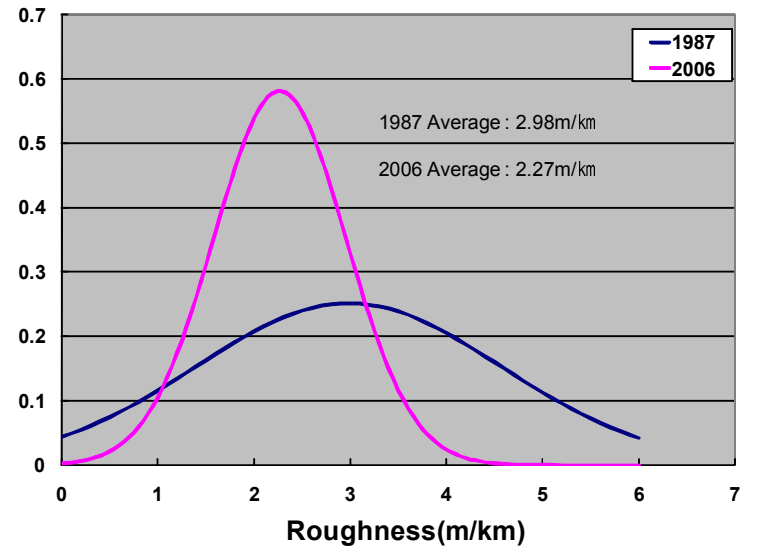

Figure 16. Comparison of longitudinal roughness

\section{ANALYSIS OF ROAD NETWORK LEVEL}

For the PMS, we have surveyed and analyzed the road network level to understand the characteristics and trend, as well as, the survey to determine the maintenance section and method to be adopted next year. The road network survey is performed for $1 \mathrm{~km}$ in every $5 \mathrm{~km}$ from the start of the road (moves $4 \mathrm{~km}$ from the start point and performs survey for $1 \mathrm{~km}$ ). Table 3 shows the summary of network level surveyed in the last 4 years.

Table 3 shows that rutting is tending downwards, while crack and longitudinal roughness are increasing. There may be various reasons for increasing crack and longitudinal roughness, but we assume that it is mainly because of extended use of polymer modified asphalt and the reinforced pavement using single-sized grain to reduce rutting. We also believe that decrease of maintenance budget since 2000 has also affected the result.

Table 3. Pavement state for the last 4 years

\begin{tabular}{|c|c|c|c|c|}
\hline Year & $\begin{array}{c}\text { Crack } \\
(\%)\end{array}$ & $\begin{array}{c}\text { Rutting } \\
(\mathrm{mm})\end{array}$ & $\begin{array}{c}\text { Roughness } \\
(\mathrm{m} / \mathrm{km})\end{array}$ & $\begin{array}{c}\text { Maintenance cost } \\
(0.1 \text { billion Won })\end{array}$ \\
\hline 2003 & 3.2 & 6.62 & 1.94 & 887 \\
\hline 2004 & 2.4 & 6.66 & 2.16 & 878 \\
\hline 2005 & 3.7 & 6.56 & 2.26 & 765 \\
\hline 2006 & 5.0 & 5.95 & 2.27 & 436 \\
\hline
\end{tabular}

\section{DIRECTION OF IMPROVEMENT OF PMS}

PMS is an objective, rational and systematic work procedure that enables us to determine the maintenance section, the maintenance method and the time through appropriate survey of the road, and to execute the maintenance budget in an efficient method.

Therefore, we plan to improve PMS to be more objective and rational as follows:

First, we need to secure objectivity and reliability of the data.

We tried to improve the survey speed and accuracy of the data, while maintaining objectivity of the result since we introduced ARAN in 1997. As the system grows older, we tend to spend more time in repairing it, and rely on visual inspection, which makes us difficult to maintain objectivity of the data. Therefore, it is required to get an alternative system, check the correction factors between the systems in advance, and apply the alternative system immediately when required to secure objectivity and reliability.

Secondly, we plan to improve rationality in selecting survey section and determining priority.

The survey section is the basic data in determining the site survey and analysis section and the homogeneous section. Therefore, it is required to check the pavement state of the national road based on the analysis of the entire road network, reduce the time by cutting down unnecessary survey, and improve the reliability.

We have used the reactive maintenance method, giving the priority to the road with the most severe damage on the pavement. We don't have the method yet to determine both the maintenance method and the time in an efficient way, but we need to improve the way to select the method and priority to get the most at a minimal cost.

Lastly, we plan to comprehensively assess and review the PMS system.

It is a question if PMS is operated systematically to articulate the works and to provide a feed back for new decision making. Since the PMS database maintains the basic configuration since its 
introduction, there is a limit to manage the old data and field survey data systematically. Therefore, we need to improve the operating system so that the system should monitor the PMS result, reflect it in the system's decision making, and improve by itself.

\section{CONCLUSIONS}

As the maintenance cost increases with the expiry of service life of the infrastructure, the way of efficiently maintaining various facilities becomes a social issue. Since its introduction, PMS has contributed to the needs of the times through change and improvement for the last 20 years.

This paper briefs the overall matters on PMS, the 2006 operation results, comparison of situations between before and after PMS, and the problems and improvement of PMS.

2006 PMS operation result shows reduction of annual maintenance length and cost by $131 \mathrm{~km}$ and 9.8 billion Won respectively. The comparison between before and after PMS shows improved pavement state and reduced maintenance cost, despite the substantial increase of traffic volume.
In view of the PMS concept, we still have a long way to go to get a perfect system. Understanding what exactly we need to improve the system is one great outcome we achieved through this study.

I hope that this study become of great use for the people who wish to understand PMS and those who plan to develop a maintenance system for other facility.

\section{REFERENCE}

[1] SAMWOO ENGINEERING/BCEOM-LCPC-KCI. (1987) Korea Highway Maintenance Management Study, Final Report.

[2] Ministry of Construction and Technology (2007) Annual Report of the National Highway Pavement Management 2006.

[3] Haas, R., Hudson R.,W. and Zaniewski J. (1994) Modern Pavement Management.

[4] Bennett, C. R. and Paterson, W.D.o. (2000) HDM-4 Mannual Vol. 5: A Guide to Callibration and Adaptation, PIARC.

[5] Lemer, A.C. (2004) Public Benefit of Highway System Preservation and Maintenance, NCHRP SYNTHESIS 330, Transportation Research Board. 